\title{
Clinical Study of Dental Cements. VII. A Study of Bridge Retainers Luted with Three Different Dental Cements
}

\author{
Ralph G. Silvey and George E. Myers \\ Crown and Bridge Department, School of Dentistry, University of Michigan, Ann \\ Arbor, Michigan 48109, USA
}

In a clinical study of three luting cements, 547 bridges and 162 crowns were permanently cemented. Patients were recalled at 6-month intervals and the restorations were examined for looseness. A pattern of retainer type, cement type and retainer success was demonstrable.

J Dent Res 57(5-6):703-707, May-June 1978.

A previous report ${ }^{1}$ discussed the success rate of three luting cements used on 547 bridges and 162 crowns. Using data collected in the same study, the success rate of the different types of retainers luted with those cements was determined and is herein reported.

\section{Materials and Methods}

A description of the materials and methods was given in the previous report. ${ }^{1}$ Briefly, the restorations involved in the study were fabricated in the Undergraduate Crown and Bridge Clinic at the University of Michigan. The three luting agents used were a zinc oxide and eugenol cement reinforced with EBA and alumina, ${ }^{*}$ a polyacrylic acid cement ${ }^{\dagger}$ and a zinc phosphate cement. + At the time of cementation the type of restoration, and the retainers and abutments used were recorded. The cementing media was mixed by one of the two investigators who then supervised the cementation. Each patient was recalled at approximately 6 -month intervals so that

\footnotetext{
Received for publication October 26, 1977.

Accepted for publication December 9. 1977

This study was supported by NIH Grant 5R01-DF-02593.

*Zebacem, L.D. Caulk Co.

$\nmid$ P.C.A., S.S. White Co.

+Tenacin, L.D. Caulk Co.
} 03 . the restoration could be examined for looseness. The restoration was recorded as successful if no looseness was detected. Patients were told to report at once should any unusual signs or symptoms arise.

\section{Results}

Table 1 illustrates the rate of success of all single restorations evaluated during the study and also shows the success rate of each type of restoration relative to the cement used.

Table 2 gives the rate of success for bridge retainers. Since a bridge generally consists of two or more retainers for each restoration and the failure of one retainer results in the failure of the restoration, no recognition is given to the retainers that remain luted in place when just restoration failures are recorded. For this reason, it is more meaningful to record the success and failure of retainers. When this is done, data from single restorations can be grouped with the bridge retainer data to give a more general view of the success or failure of cementation. This information is shown in Table 3.

It should be noted that some patients had more than one restoration placed that were included in the study. A survey of the results of a previous study revealed no pattern of success or failure that indicated the mouths of some subjects influenced the study results; therefore, no stipulation limiting the number of restorations included per patient was made.

$$
\text { Statistical Analysis }
$$

The $\mathrm{Chi}^{2}$ test was selected as a simple and straightforward method of analyzing the data in Table 3 . Only certain grouping 
TABLE 1

SUCCESS OF EACH TYPE OF SINGLE RESTORATION

\begin{tabular}{cllcc}
\hline & & C.C. & $3 / 4 \mathrm{C}$. & M.O.D. \\
\hline All three & Total & 119 & 27 & 4 \\
cements & Success & 117 & 27 & 3 \\
& Percent & $98.3 \%$ & $100 \%$ & $75 \%$ \\
Zinc Oxide & Total & 42 & 10 & 2 \\
Eugenol & Success & 41 & 10 & 2 \\
& Percent & $97.6 \%$ & $100 \%$ & $100 \%$ \\
Polyacryic & Total & 30 & 12 & 2 \\
Acid & Success & 29 & 12 & 1 \\
& Percent & $96.7 \%$ & $100 \%$ & $50 \%$ \\
Zinc & & & & \\
Phosphate & Sotal & 47 & 5 & 0 \\
& Success & 47 & 5 & 0 \\
\hline NOTE: Some patients were not available for recall so 12 single restorations were not evaluated.
\end{tabular}

of the data, however, produced valid results. This occurred because two assumptions of the $\mathrm{Chi}^{2}$ test were violated by the data, i.e. (1) that no expectation be less than 1 and (2) not more than $20 \%$ of the expectation should be less than 5 .

When data were grouped to evaluate cement type across retainer type the mesiooccluso-distal protective cusp onlay (MOD) retainer had to be eliminated because there were too few observations for analy- sis. So few failures with the zinc phosphate cement were recorded that a valid statistical analysis could not be done.

When data were grouped so that retainer types were compared across cements too few failures were observed for the MOD and pinledge (P.L.) retainers to validly test for association of success-failure rates with cement type.

Tables 4 and 5 show the $\chi^{2}$ analysis of a reinforced zinc oxide and eugenol cement

TABLE 2

SUCCESS OF EACH TYPE OF BRIDGE RETAINER

\begin{tabular}{llcccc}
\hline \hline & & C.C. & 3/4 C. & M.O.D. & Pinl. \\
\hline All three & Total & 542 & 439 & 25 & 76 \\
cements & Success & 530 & 423 & 25 & 71 \\
& Percent & $97.8 \%$ & $96.4 \%$ & $100 \%$ & $93.4 \%$ \\
& & & & & \\
Zinc Oxide & Total & 184 & 158 & 11 & 30 \\
Eugenol & Success & 181 & 150 & 11 & 26 \\
& Percent & $98.4 \%$ & $94.9 \%$ & $100 \%$ & $86.7 \%$ \\
Polyacrylic & Total & 210 & 145 & 9 & 24 \\
Acid & Success & 204 & 138 & 9 & 23 \\
& Percent & $97.1 \%$ & $95.2 \%$ & $100 \%$ & $95.8 \%$ \\
Zinc & & & & & \\
Phosphate & Total & 148 & 136 & 5 & 22 \\
& Success & 145 & 135 & 5 & 22 \\
& Percent & $98 \%$ & $99.3 \%$ & $100 \%$ & $100 \%$ \\
\hline
\end{tabular}


TABLE 3

SUCCESS RATE OF SINGLE RESTORATIONS AND BRIDGE RETAINERS

\begin{tabular}{llccll}
\hline \hline & & C.C. & 3/4C. & M.O.D. & Pinl. \\
\hline All three & Total & 661 & 466 & 29 & 76 \\
cements & Success & 647 & 450 & 29 & 71 \\
& Percent & $97.9 \%$ & $96.6 \%$ & $96.6 \%$ & $93.4 \%$ \\
& & & & & \\
Zinc Oxide & Total & 226 & 168 & 13 & 30 \\
Eugenol & Success & 222 & 160 & 13 & 26 \\
& Percent & $98.2 \%$ & $95.2 \%$ & $100 \%$ & $86.7 \%$ \\
& & & & & \\
Polyacrylic & Total & 240 & 157 & 11 & 24 \\
Acid & Success & 233 & 150 & 10 & 23 \\
& Percent & $97.1 \%$ & $95.5 \%$ & $90.9 \%$ & $95.8 \%$ \\
Zinc & & & & & \\
Phosphate & Total & 195 & 141 & 5 & 22 \\
& Success & 192 & 140 & 5 & 22 \\
& Percent & $98.5 \%$ & $99.3 \%$ & $100 \%$ & $100 \%$ \\
\hline
\end{tabular}

TABLE 4

CHI SQUARE ANALYSIS

EBA CEMENT

\begin{tabular}{|c|c|c|c|c|c|c|}
\hline & \multicolumn{2}{|c|}{$\begin{array}{c}\text { Observed } \\
\text { Frequency }\end{array}$} & \multicolumn{2}{|c|}{$\begin{array}{l}\text { Expected } \\
\text { Frequency }\end{array}$} & \multicolumn{2}{|c|}{$\begin{array}{c}\text { Contributions to } \\
\mathrm{Chi}^{2}\end{array}$} \\
\hline & Success & Failure & Success & Failure & Success & Failure \\
\hline C.C. & 222 & 4 & 217.14 & 8.53 & 0.09 & 2.44 \\
\hline $3 / 4 \mathrm{C}$. & 160 & 8 & 161.66 & 6.34 & 0.02 & 0.43 \\
\hline P.L. & 26 & 4 & 28.87 & 1.13 & 0.29 & 7.29 \\
\hline
\end{tabular}

TABLE 5

CHI SQUARE ANALYSIS

PCA CEMENT

\begin{tabular}{|c|c|c|c|c|c|c|}
\hline & \multicolumn{2}{|c|}{$\begin{array}{l}\text { Observed } \\
\text { Frequency }\end{array}$} & \multicolumn{2}{|c|}{$\begin{array}{l}\text { Expected } \\
\text { Frequency }\end{array}$} & \multicolumn{2}{|c|}{$\begin{array}{c}\text { Contributions to } \\
\mathrm{Chi}^{2}\end{array}$} \\
\hline & Success & Failure & Success & Failure & Success & Failure \\
\hline C.C. & 233 & 7 & 231.45 & 8.55 & 0.01 & 0.28 \\
\hline $3 / 4 \mathrm{C}$ & 150 & 7 & 151.41 & 5.59 & 0.01 & 0.36 \\
\hline P.L. & 23 & 1 & 23.14 & 0.86 & 0.00 & 0.02 \\
\hline
\end{tabular}


TABLE 6

CHI SQUARE ANALYSIS

THREE-QUARTER CROWNS COMPARED ACROSS CEMENTS

\begin{tabular}{|c|c|c|c|c|c|c|}
\hline & \multicolumn{2}{|c|}{$\begin{array}{l}\text { Observed } \\
\text { Frequency }\end{array}$} & \multicolumn{2}{|c|}{$\begin{array}{l}\text { Expected } \\
\text { Frequency }\end{array}$} & \multicolumn{2}{|c|}{$\begin{array}{c}\text { Contributions to } \\
\mathrm{Chi}^{2}\end{array}$} \\
\hline & Success & Failure & Success & Failure & Success & Failure \\
\hline \multicolumn{7}{|l|}{ Zinc Oxide } \\
\hline Eugenol & 160 & 8 & 162.2 & 5.8 & 0.0 & 0.9 \\
\hline \multicolumn{7}{|l|}{ Polyacrylic } \\
\hline Acid & 150 & 7 & 151.6 & 5.4 & 0.0 & 0.5 \\
\hline \multicolumn{7}{|l|}{ Zinc } \\
\hline Phosphate & 140 & 1 & 136.2 & 4.8 & 0.1 & 3.0 \\
\hline
\end{tabular}

and a polyacrylic acid cement. Note that the MOD retainer was omitted. This was done because the lack of failure of this retainer caused the $\chi^{2}$ analysis to be invalid.

Table 4 shows that when zinc oxide and eugenol cement reinforced with EBA and alumina is used as a luting agent, the pinledge retainer fails more frequently than would be expected.

Table 5 shows that when a polyacrylic acid cement is used as a luting agent there is a slight trend for the three-quarter crown retainer to fail more frequently than other retainer types but this finding was not statistically significant.

When data were grouped to compare the retainer type to the cement used, the analysis was limited by problems that were previously described. One test was valid, however, and that is summarized in Table 6 which compares the three-quarter crown retainer to the type of cement used. The table shows that the number of failures of three-quarter crowns luted in place with zinc phosphate cement contributes most to the $\chi^{2}$ findings. Comiparison of the frequency and expected frequency values clearly indicates that there were fewer failures than would be expected.

\section{Discussion}

In a clinical study such as this where the treatment of patients is the first concern, it is difficult to control all parameters to the degree desired and still complete the study in a reasonable length of time. Because the needs of the patient were considered first, many different retainer types were used and this added one more variable that had to be considered in the study. The interaction of these two factors, i.e. limited time and, therefore, limited number of restorations, made the use of some retainer types too infrequent to get adequate data for sound statistical analysis. It is actually a compliment to the dental profession when it is noted that the lack of an adequate number of retainer failures was the cause of invalidity for many of the statistical tests that were performed on the data. Only by eliminating the cement zinc phosphate which had few failures and the infrequently used MOD retainer from analysis was it possible to do valid statistical testing.

Examination of the data collected on the reinforced zinc oxide and eugenol cement revealed that this cement probably should not be used to lute pinledge restorations. Table 4 also reveals that the failure of complete crowns was less than would be expected.

The polyacrylic acid (Table 5) cement seems to have a very slight trend to fail more frequently than expected when used with three-quarter crown retainers. This result, however, is not significant and it could have occurred simply by chance.

When just the three-quarter crown retainer is compared to the cement used as a 
luting agent (Table 6) it is interesting to note that zinc phosphate had fewer failures than would be expected. This could be taken as evidence that zinc phosphate is the cement of choice if pulpal irritation is not expected to be a problem.

\section{Summary}

Over a three-year period, 547 bridges and 162 crowns were finally cemented with one of three dental cements. At the time of cementation, the type of retainer and cement used was recorded. Patients were recalled at 6 -month intervals and the bridge or crown was examined for looseness.

\section{Conclusions}

When zinc oxide and eugenol cement reinforced with EBA and alumina is used as a luting agent for final cementation, the pinledge retainer will fail more frequently than either the complete crown or threequarter crown retainer.

When polyacrylic acid cement is used as a luting agent the complete crown, threequarter crown and pinledge retainers will be equally successful.

If only the three-quarter crown is used as a retainer the highest rate of success will be realized when it is luted with zinc phosphate rather than a reinforced zinc oxide and eugenol or a polyacrylic acid cement.

\section{Reference}

1. Silvey, R.G., and Myers, G.E.: Clinical Study of Dental Cements VI: A Study of Zinc Phosphate, EBA Reinforced OxideEugenol and Polyacrylic Acid Cements as Luting Agents in Fixed Prostheses, $J$ Dent Res 56:1215, 1977. 